\title{
Improving health through diet and exercise in children
}

Running title: child health diet and exercise

\section{Elaine Rush, PhD}

Child Health Research Centre, Faculty of Health and Environmental Sciences, Auckland University of Technology, Auckland, New Zealand

\section{Tara Coppinger, $\mathbf{P h D}$}

Department of Sport, Leisure and Childhood Studies, Cork Institute of Technology, Cork, Ireland

\section{Corresponding author}

Elaine Rush

Faculty of Health and Environmental Science

Auckland University of Technology, Private Bag 92006, Auckland 1142, New Zealand Tel: 006499219758

Fax: 0064299219960

Email: elaine.rush@aut.ac.nz 


\begin{abstract}
We know that nutritious foods and quality physical activity are two of the fundamental needs for normal growth and development of children. Food based dietary guidelines and physical activity recommendations have universal evidence base but the teaching of fundamental movement skills is limited without support. Given the importance of prevention of childhood obesity the distal drivers also need to be examined including poverty. Interventions trialled in carefully controlled conditions while shown to have efficacy are not effective in the real world. There is a need for more research and rigorous evaluation of interventions in combinations of settings and with innovative research designs rather than the traditional randomised controlled trial of limited duration. What works needs to be defined and measured differently. One example of a 14 year and ongoing physical activity and nutrition intervention, Project Energize in the Waikato region of New Zealand is described along-side innovative measures of effectiveness such as time to run $550 \mathrm{~m}$ and assessment of dental health. Translation of research findings into public health actions is a challenge alongside the effects of global climate change, trade agreement, multinational companies and the influence of social media in informing people. The need is to take action now, the child cannot wait.
\end{abstract}

\title{
What is already known
}

For optimal health and growth, children need to start life as a healthy zygote and be continuously exposed to an environment that provides, in adequate quantities and quality, the many needs for life. Nutritious food and regular physical activity (PA) are two of the most fundamental requirements that support normal growth and development, with adverse early life experiences found to have lasting negative effects on health and wellbeing across the life course $^{1}$. Breastfeeding ${ }^{2}$ and early-in-life interventions ${ }^{3}$ that improve the internal and external environment also have more positive influences on the life trajectory than those delivered later in life.

Provision of adequate nourishment is complex; too much or too little and timing of the essential and non-essential nutrients can cause harm across the life course. As a result, a focus on foods, rather than nutrients is necessary to inform population health, policy and planning. Food-based dietary guidelines (FBDG) are simple messages that provide a basic 
framework to the general public on what they should be eating to foster healthy eating habits and lifestyles ${ }^{4}$.

Universally these guidelines encourage the consumption of combinations of wholesome foods, including a variety of fruit and vegetables, good sources of protein including meat, eggs, dairy and pulses and staples such as wholegrains and starchy vegetables for energy. There is, however, a disconnect in the food supply chain resulting in many children, from both developed and developing countries, being food insecure. Food insecurity refers to lack of access to nutritious foods in sufficient quantities to maintain good health. The foods must be culturally and socially acceptable ${ }^{5}$.

The disconnects for the consumer at the end of the supply chain include cost, availability, time constraints for preparation and access to wholesome foods ${ }^{6}$ and because of the added complexity of parents/carers being the sole providers of children's food, children are also limited in their lifestyle and individual choices in relation to the foods that they predominantly consume.

The ability to physically move is an inherent characteristic of living animals. However, the quality and quantity of PA provided to children is, in part, subject to the knowledge, understanding and skill of parents, families and the education system and the environment. Consequently, the opportunity to learn the fundamental movement skills of object control, locomotion and stability for some children is limited without support of experts ${ }^{7}$, which could ultimately lead to a lack of physical competence to participate in a broader range of activities as children age ${ }^{8}$. Fundamental movement skill (FMS) competence is positively associated with levels of $\mathrm{PA}^{9,10}$ and interventions to improve FMS are effective in improving skill ${ }^{11,12}$ but whether such interventions can positively affect child growth and health are not yet apparent, primarily due to the short time frame often allocated to evaluation of such initiatives ${ }^{13}$. 
Traditionally, the main outcome measure of nutrition and PA trials is body mass index (BMI), which is defined as mass relative to height squared. BMI in children is a moving, or rather, growing target and increases in height and weight occur in spurts and at different times. The way that a child's growth trajectory is assessed is against reference curves such as those provided by the World Health Organisation ${ }^{14}$. By focusing primarily on BMI, this view constrains understanding of other outcomes that may be equally important "in the desirable growth trajectory to health". Optimal growth is not just physical size or adequate nutrients and movement. There are mental, and emotional dimensions and the family, community, social and political environment have a large part to play in the supportive path to health. It is not just telling children to eat better and exercise more, or regulating the food industry or schools: environments and society need to change- incrementally but permanently. But what may be more important for diet and PA is what is not eaten and what is not done. For example, not consuming fruit and vegetables, consuming sugary drinks instead of water and spending long periods in sedentary occupations such as screen time. The quality of the micro and macro environment and their context need to be looked at and permanent changes need to take place so that quality, 'huff and puff' PA and healthier eating and drinking become the easy, habitual norm. For example to ensure that safe, free water is available at all times for children ${ }^{15}$.

It could be argued that if child poverty was prevented then childhood obesity would also be reduced ${ }^{16}$. The challenge therefore is huge but intersectorial and bold action is required if there is to be any impact of child based health promotion interventions. Interventions for childhood obesity have the intent to improve diet and increase PA in different settings including public health clinics, schools, homes, community programmes and through environmental change and community support ${ }^{7}$. We know that in order for interventions to receive funding and government support, politicians and health agencies demand peer- 
reviewed evidence for action; for example that a sugar tax will reduce obesity ${ }^{17}$ and dental decay ${ }^{18}$. Interventions are also more likely to be funded if they show that they are feasible, cost effective and reduce lifetime costs ${ }^{19}$ and that outcomes can be measured within a relatively short time frame. Yet, even though interventions are trialled in carefully designed, randomised and controlled settings, their outcomes have been "disappointing" 7 . Limited length of delivery time, compromised secular changes, interactions with external environments, confinement to settings only where informed consent for measurement is available and very short follow-up times have all been provided as reasons as to why poor effects have been found.

Another consideration includes the use of a randomised control trial (RCT). Although they are recommended, long term RCT's cannot be undertaken and they do not measure effectiveness in the real world. Real-world samples could be biased due to transience, lack of consent for follow-up and the sample not equitably representing the population of importance, which can widen inequities and add to the problem. There are also ethical questions relating to whether or not it is appropriate to withhold treatment from a control group. Secondly, we know from the Dutch famine study ${ }^{20}$, and the evidence underpinning the Barker hypothesis ${ }^{21}$ that although negative outcomes of an early life insult may not affect immediate health status, the consequences may be seen in later decades, when the resilience and plasticity of the body is reduced and the capacity to adapt is compromised.

\section{What we are getting to know now}

Research continues to show that improving childhood health through diet and exercise alone is complex ${ }^{22}$ and a focus on diet and PA is not enough ${ }^{7}$. There is a need for more research and rigorous evaluation of interventions in combinations of settings and with innovative research designs. The focus needs to be placed on interventions that are environmental, political including taxes ${ }^{23}$ and use health informatics science to problem solve and make 
decisions. A recent example of a "null finding" limited by the RCT design and length of intervention is the WAVE study ${ }^{24}$, published in the BMJ and in receipt of widespread and international media attention. The study concluded that after a 12 month intervention, which was only applied during school time, there were no statistically significant effects on BMI at 15, 30 and 39 months from baseline. The media jumped on this bandwagon stating that "antiobesity programmes in primary schools don't work," failing to recognise that, as the authors stated, schools are only one part of the community and unlikely to impact on obesity without wider and ongoing support across multiple sectors and environments.

An example, however, of a successful and ongoing intervention that has proven to reduce body fat in children is Project Energize; delivered since 2004 in the Waikato region of New Zealand. The intervention is delivered to all primary schools (44,000, 242 schools) in the region. and foresight and commitment by the Waikato District Health board to this health service has resulted in the unique situation where a $\mathrm{RCT}^{25}$ led to funding and action over 14 years, with no current plans for funding to cease.

Measurements of 4804 children in 2011 demonstrated that amongst children participating in Project Energize, the prevalence of obesity and overweight was lower, and they could run $550 \mathrm{~m}$ about $10 \%$ faster than children measured in 2004 and $2006^{26}$. The intervention is also cost effective ${ }^{25}$ and continues to cost less than a visit to the doctor (\$NZ45/child/year $~ 20 \mathrm{c}$ per school day).

New Zealand should be very proud of this ground breaking public health initiative, which the current (2017-) Labour government have said they will continue to support and even roll out to the whole of New Zealand. There is not an equivalent elsewhere in the world, particularly when it is in partnership with, and has positive outcomes for, indigenous people. In recognition of the need for earlier intervention, the Ministry of Health have now funded within the Ministry of Health child and maternal health portfolio, "Under 5 Energize". This is 
an adaptation of the original Energize nutrition and PA intervention that is being delivered to 121 early childhood education centres in New Zealand since mid 2013. The impact of this intervention has been assessed using a national health check of 4 year old children and this data has shown improvements in the prevalence of visible dental decay in those participating in the programme ${ }^{27}$.

Such findings provide evidence to support the need to now routinely measure the impact of interventions through additional and ongoing measures such as quality of life, fundamental movement skill competence (550 m run) ${ }^{28}$ and improvement of dental health. The challenge for health promotion systems is not what to do but how to do it, given all the other competing drivers and enablers of an environment supportive of a healthier food supply and quality PA.

\section{What do we need to know in future}

We don't yet know how best to ensure children habitually choose wholesome, nutritious foods over energy-dense, nutrient poor options and partake in enough PA to benefit their ongoing health and quality of life. We are getting to know better how to translate research findings into public health but when the treatment unit is the environment, it is harder to justify expenditure unless the whole country or region is changed. Evidence of the effects of large scale, longer delivered interventions that encapsulate whole populations of children in society need to be explored and the impact measured with routinely collected information, rather than RCT's. We need to know better how to measure impact without interfering with the system or biasing because of need for informed consent. For instance, can we measure from specific food sales the health of the food supply, by geographic area and deprivation? We also need to know how to communicate science better, to be critical but in a constructive way and in partnership with the people who stand to benefit and those who have influence. Until research is unequivocal, we, the science community, need to continue to challenge existing policies and action through informed, evidence based research and accept that 
obesity is a global, socially transmitted disease ${ }^{29}$ where no country or region is exempt ${ }^{30}$. But the challenge is wider - no country is immune from the effects of global climate change, trade agreement, multinational companies and the influence of social media in informing people. We are getting to understand better the effect of urbanisation on reducing market gardening areas for cities, the inability to supply portable water especially in war and disaster, the huge effects of inequality in society and the widening gap between the rich and poor. There is huge capacity to collectively put past, current and future data sets together to identify areas of most need and to predict and forecast change for future generations. We talk about inter-sectorial interventions to improve child health, the need to end child obesity ${ }^{31}$ but faster action is needed and investment provided where it will count most. There needs to be an acceptance from those who invest at all levels; in all policies, laws and actions, that children are not mini adults and the effects of such investment should not be underestimated, even if they may not be seen immediately. The need is to do something now. The rights of the child and the rights to food and water should be foremost. The cost of not doing anything, now, is too high for future generations.

Conflict of Interest The authors declare that they have no conflict of interest.

\section{References}

1. Moss JL, Harris KM. Impact of maternal and paternal preconception health on birth outcomes using prospective couples' data in Add Health. Arch Gynecol Obstet. 2015; 291: 287-298.

2. Victora CG, Bahl R, Barros AJ, Franca GV, Horton S, Krasevec J et al. Breastfeeding in the 21st century: epidemiology, mechanisms, and lifelong effect. Lancet. 2016; 387: 475490. 
3. Hanson M, Gluckman P. Developmental origins of noncommunicable disease: population and public health implications. Am J Clin Nutr. 2011; 94: 1754S-1758S.

4. Food and Agriculture Organisation of the United Nations. Food-based dietary guidelines. 2018. http://www.fao.org/nutrition/nutrition-education/food-dietaryguidelines/en/. Accessed April, 2017.

5. Ke J, Ford-Jones EL. Food insecurity and hunger: A review of the effects on children's health and behaviour. Paediatr Child Health. 2015; 20: 89-91.

6. Leroy JL, Ruel M, Frongillo EA, Harris J, Ballard TJ. Measuring the Food Access Dimension of Food Security: A Critical Review and Mapping of Indicators. Food Nutr Bull. 2015; 36: 167-195.

7. Bleich SN, Vercammen KA, Zatz LY, Frelier JM, Ebbeling CB, Peeters A. Interventions to prevent global childhood overweight and obesity: a systematic review. Lancet Diabetes Endocrinol. 2018; 6: 332-346.

8. Coppinger T. Sport, health and physical activity in children. In: Parnell D, Krustrup P (eds). Sport and Health: Exploring the Current State of Play. Routledge: London, 2017. p 256.

9. Barnett LM, Lai SK, Veldman SLC, Hardy LL, Cliff DP, Morgan PJ et al. Correlates of Gross Motor Competence in Children and Adolescents: A Systematic Review and MetaAnalysis. Sports Med. 2016; 46: 1663-1688.

10. Robinson LE, Stodden DF, Barnett LM, Lopes VP, Logan SW, Rodrigues LP et al. Motor Competence and its Effect on Positive Developmental Trajectories of Health. Sports Med. 2015; 45: 1273-1284.

11. Han A, Fu A, Cobley S, Sanders RH. Effectiveness of exercise intervention on improving fundamental movement skills and motor coordination in overweight/obese children and adolescents: A systematic review. J Sci Med Sport. 2018; 21: 89-102. 
12. Mitchell B, McLennan S, Latimer K, Graham D, Gilmore J, Rush E. Improvement of fundamental movement skills through support and mentorship of class room teachers. Obes Res Clin Pract. 2013; 7: e230-234.

13. Rush E, Simmons D. Physical activity in children: prevention of obesity and type 2 diabetes. Med Sport Sci. 2014; 60: 113-121.

14. de Onis M, Onyango AW, Borghi E, Garza C, Yang H. Comparison of the World Health Organization (WHO) Child Growth Standards and the National Center for Health Statistics/WHO international growth reference: implications for child health programmes. Public Health Nutr. 2006; 9: 942-947.

15. Rush EC. Water: neglected, unappreciated and under researched. Eur J Clin Nutr. 2013; 67: 492-495.

16. Lee H, Andrew M, Gebremariam A, Lumeng JC, Lee JM. Longitudinal associations between poverty and obesity from birth through adolescence. Am J Public Health. 2014; 104: e70-76.

17. Cabrera Escobar MA, Veerman JL, Tollman SM, Bertram MY, Hofman KJ. Evidence that a tax on sugar sweetened beverages reduces the obesity rate: a meta-analysis. $B M C$ Public Health. 2013; 13: 1072.

18. Schwendicke F, Thomson WM, Broadbent JM, Stolpe M. Effects of Taxing SugarSweetened Beverages on Caries and Treatment Costs. J Dent Res. 2016; 95: 1327-1332. 19. Hamilton D, Dee A, Perry IJ. The lifetime costs of overweight and obesity in childhood and adolescence: a systematic review. Obes Rev. 2018; 19: 452-463.

20. Painter RC, Roseboom TJ, Bleker OP. Prenatal exposure to the Dutch famine and disease in later life: an overview. Reprod Toxicol. 2005; 20: 345-352.

21. de Boo HA, Harding JE. The developmental origins of adult disease (Barker) hypothesis. Aust N Z J Obstet Gynaecol. 2006; 46: 4-14. 
22. Wang Y, Cai L, Wu Y, Wilson RF, Weston C, Fawole O et al. What childhood obesity prevention programmes work? A systematic review and meta-analysis. Obes Rev. 2015; 16: 547-565.

23. Summers LH. Taxes for health: evidence clears the air. Lancet. 2018.

24. Adab P, Pallan MJ, Lancashire ER, Hemming K, Frew E, Barrett T et al. Effectiveness of a childhood obesity prevention programme delivered through schools, targeting 6 and 7 year olds: cluster randomised controlled trial (WAVES study). BMJ. 2018; 360: $\mathrm{k} 211$.

25. Rush E, Reed P, McLennan S, Coppinger T, Simmons D, Graham D. A school-based obesity control programme: Project Energize. Two-year outcomes. Brit J Nutr. 2012; 107: 581-587.

26. Rush E, McLennan S, Obolonkin V, Vandal AC, Hamlin M, Simmons D et al. Project Energize: whole-region primary school nutrition and physical activity programme; evaluation of body size and fitness 5 years after the randomised controlled trial. Br J Nutr. 2014; 111: 363-371.

27. Rush E, Obolonkin V, Young L, Kirk M, Tseng M. Under 5 Energize: Tracking Progress of a Preschool Nutrition and Physical Activity Programme with Regional Measures of Body Size and Dental Health at Age of Four Years. Nutrients. 2017; 9.

28. Rush E, McLennan S, Obolonkin V, Cooper R, Hamlin M. Beyond the randomised controlled trial and BMI--evaluation of effectiveness of through-school nutrition and physical activity programmes. Public Health Nutr. 2015; 18: 1578-1581.

29. Allen LN, Feigl AB. Reframing non-communicable diseases as socially transmitted conditions. Lancet Glob Health. 2017; 5: e644-e646.

30. The Lancet Child \& Adolescent Health. No one is exempt in the fight against childhood obesity. The Lancet Child \& Adolescent Health. 2017; 1: 79. 
31. Nishtar S, Gluckman P, Armstrong T. Ending childhood obesity: a time for action. Lancet. 2016; 387: 825-827. 